\title{
EDSON Rosa DA SiLVA, NA MEMÓRIA EDSON ROSA DA SILVA, IN MEMORIAM
}

\section{Marcelo Jacques de Moraes \\ ORCID 0000-0001-8695-3280}

\author{
Universidade Federal do Rio de Janeiro \\ Rio de Janeiro, RJ, Brasil
}

\section{Resumo}

Palavras pronunciadas em 12/02/2021 na Congregaçáo da Faculdade de Letras da UFRJ em homenagem a Edson Rosa da Silva, Professor Titular de Língua e Literatura Francesa do Departamento e do Programa de Pós-Graduação em Letras Neolatinas e editor fundador da Alea.

Palavras-chave: Edson Rosa da Silva; literatura francesa; ensaios.

\begin{abstract}
Words uttered on 02/12/2021 at the Congregation of the Faculty of Letters of UFRJ in honor of Edson Rosa da Silva, Professor of French Language and Literature of the Department and of the Postgraduate Program in Neo-Latin Letters and founding editor of Alea.
\end{abstract}

Keywords: Edson Rosa da Silva; French literature; essays.

\section{Résumé}

Paroles prononcées le 02/12/2021 à la Congrégation de la Faculté des Lettres de l'UFRJ en l'honneur d'Edson Rosa da Silva, Professeur de Langue et Littérature Françaises du Département et du Laboratoire de Recherche en Lettres Néolatines et éditeur fondateur de la revue Alea.

Mots-clés: Edson Rosa da Silva; littérature française; essais. 
O texto que segue reproduz as palavras que pronunciei na Congregação da Faculdade de Letras da UFRJ no dia 12 de fevereiro de 2021, em sessão extraordinária dedicada a homenagear a trajetória e a memória de Edson Rosa da Silva, Professor Titular do Departamento de Letras Neolatinas e do Programa de Pós-Graduaçáo em Letras Neolatinas, que nos deixara em 30 de dezembro de 2020.

Queridos e queridas colegas, eu gostaria de estar hoje aqui, junto à nossa Congregação, defendendo o pedido de concessão de título de Professor Emérito da Faculdade de Letras da UFRJ ao Professor Titular de Língua e Literatura Francesa Edson Rosa da Silva. Já havia conversado a respeito no ano passado com nossa diretora Sonia Reis e com o chefe de Departamento de Letras Neolatinas Luiz Carlos Balga, e combinamos que aguardaríamos sua recuperação dos problemas de saúde que o abateram no segundo semestre para dar sequência ao processo formal. Infelizmente isso não foi possível, e resta-nos agora, nesta homenagem, celebrar sua memória. Para começar, resumirei brevemente sua trajetória profissional, apenas pontuando alguns momentos de uma vida intelectual e institucional extremamente prolífica e rica.

Edson atuou como professor de Língua e Literatura Francesa desta Faculdade durante 45 anos. Começou em 1975, depois de um mestrado na França, na Universidade de Toulouse, onde desenvolveu um trabalho sobre André Malraux, escritor de cuja extensa e complexa obra, romanesca e ensaística, ele se tornaria com o passar dos anos notório especialista. De retorno ao Brasil, paralelamente às aulas ministradas na Graduação da Faculdade (onde se graduara em 1971), Edson fez um novo mestrado e um doutorado em Letras Neolatinas, concluído em 1984. Começou a atuar como docente na pós-graduação já em 1985 e ocupou nos anos seguintes diversos cargos acadêmicos relevantes na Faculdade de Letras da UFRJ: foi, entre outros, Coordenador do Programa de Pós-Graduação em Letras Neolatinas, que ajudou a construir. Tornou-se professor titular em 1998. Em 1999, quando assumi a coordenação do Programa, criamos juntos a revista Alea: Estudos Neolatinos, que editamos juntos até 2019. Foi a primeira revista da área de Letras a ser indexada pela Coleção Scielo, em 2003. Edson afastou-se duas ou três vezes por problemas de saúde na última década, mas sempre voltou e atuou na graduação e na pós-graduação até se aposentar definitivamente, no final de 2019.

Como pesquisador, seu trabalho se projetou para muito além dos muros da UFRJ. No plano nacional, teve significativa atuação nas áreas de Literatura Francesa e de Literatura Comparada, com atuação relevante em associaçôes científicas, tendo participado ativamente das direçôes da ANPOLL 
e da ABRALIC, nos anos 1990 e 2000. Bolsista de produtividade do CNPq desde o final dos anos 1980, foi membro do Comitê de Assessoramento da agência nos anos 2000. E especialmente a partir de seu trabalho com a obra de Malraux construiu sólida reputação internacional, participando de colóquios e de publicaçóes dedicados ao escritor em diversos países ao longo de mais de três décadas. Fez estágios de pós-doutorado em Konstanz e em Freiburg, na Alemanha, nos anos 1990, onde começou a desenvolver uma articulação extremamente original entre o pensamento estético de Malraux e o de Walter Benjamin, que resultaria em vários ensaios publicados no Brasil e no exterior. E fez ainda um estágio de pós-doutorado em Paris 7, em 2008, onde começou uma pesquisa visando à traduçáo do sofisticado diálogo de Malraux com Picasso intitulado $A$ Cabeça de Obsidiana.

Foram, até 2019, três livros, quase uma centena de artigos em revistas e livros, sendo pelo menos um quarto deles em publicaçóes internacionais, e incontáveis participaçôes em eventos no Brasil e no exterior. Notem-se, como balizas importantes de sua trajetória, o livro $A s$ (não-) fronteiras espaciotemporais em L'Espoir de Andre Malraux, publicado em 1978, a organização e tradução, em 1998, dos discursos proferidos por Malraux no Brasil em 1959 e, em 2015, a redação de vários verbetes do Dictionnaire André Malraux publicado pela coleção Classiques das ediçóes Garnier.

Edson também organizou diversos eventos nacionais e internacionais, entre os quais um importante colóquio na UFRJ em homenagem a Malraux pelos 20 anos de sua morte, em 1996, com a presença dos grandes especialistas franceses, e um colóquio pelos 150 anos das Flores do mal, de Baudelaire, em 2007, que eu e Paula Glenadel tivemos a honra de organizar com ele, e que teve também enorme repercussão, com a presença de especialistas do Brasil e do exterior. Não entrarei aqui em mais detalhes relativos à produção intelectual de Edson ao longo de seus 50 anos na UFRJ (cinco como aluno de graduaçáo e 45 como professor), creio que este breve relato permite ter uma ideia da importância de seu trabalho.

Mas eu gostaria especialmente de destacar que o terrível ano de 2020, o primeiro ano de Edson como aposentado, que acreditaríamos ainda mais terrível para ele pela fragilidade de sua saúde, foi particularmente produtivo e alegre. As circunstâncias o levaram a isolar-se na casa da família em Itacoatiara com Teresa, sua mulher, suas filhas Adriana e Daniela, e sua neta Clara. Em meio a tantas provas por que passara na última década, com dezenas de internaçóes hospitalares por conta de tantos problemas de saúde, seu entusiasmo com esse novo cotidiano era patente, a ponto de voltar com garra a dois projetos que vinha adiando havia alguns anos: a organização de uma coletânea de ensaios produzidos nos últimos 20 anos, que intitulou $A$ reflexão da literatura, e a revisão da tradução de $A$ Cabeça de obsidiana, 
de Malraux, que, como eu disse, ele tinha iniciado em 2008 (Trabalho que fico particularmente feliz e orgulhoso por tê-lo estimulado a concluir para submeter ao edital de ensaios traduzidos que criamos na Editora UFRJ em 2020, no início de minha gestáo como diretor. Que ele teve tempo de ver aprovado pelo Conselho da Editora e que será publicado este ano). ${ }^{1}$

Mas acho que a maior homenagem que posso fazer a Edson aqui é fazer ouvir a sua voz, a clareza com que se expressava, a densidade e a paixáo que vinham de suas reflexóes sobre a arte e a literatura, e que emanavam em suas aulas e nas conversas que se podia ter com ele. Da coletânea, que ele concluiu, mas não teve tempo de ver impressa, eu gostaria de ler um trecho do último ensaio do livro, intitulado "As Flores do mal inspirando outras cidades", que escolho por três razōes. Primeiramente porque expóe um momento que considero exemplar do pensamento e da sensibilidade de Edson sobre o que chamou de reflexão da literatura. Em segundo lugar, razão mais pessoal, pela paixão em comum que tínhamos por Baudelaire, sobre quem tanto conversamos, na universidade e fora dela. E que escolho ainda porque me emociona particularmente pelo fato de ter estado com ele em 2001 na cidadezinha do interior da França de que ele fala aqui, aquela em que o narrador de Em Busca do tempo perdido, de Marcel Proust - outra paixão comum - situa suas lembranças da infância e da adolescência. Escreve Edson:

Como leitores de Proust, estamos afeitos à descrição literária da pequena cidade de Combray, imagem de um paraíso terrestre que traz alegria à infância e que abriga as ilusôes, as esperanças, os sofrimentos e os amores infantis do herói de Em busca do tempo perdido. Aí lemos magníficas descriçōes: a igreja "que resumia a cidade, que a representava, que falava dela e por ela à distância [...] e que, qual pastor, suas ovelhas mantinha junto a si, em pleno campo, contra o vento, o dorso acinzentado de lá das casas reunidas, cercadas por um resto de muralhas da Idade Média" (PROUST, 1968, p. 58-59); ou as ninfeias do rio Vivonne, que formam verdadeiros jardins, salpicados de flores vermelhas como morangos, de coração escarlate e bordas brancas, ou de variadas tonalidades, mais pálidas, menos lisas, mais granuladas, mais dobradas e "dispostas ao acaso em ornamentos espiralados táo graciosos que pareciam flutuar à deriva como após o desfolhamento de uma 'festa galante', como rosas de uma guirlanda desfeita" (PROUST, 1968, p. 203); ou os pilriteiros em flor, descritos como obras-primas, como o ornamento de uma festa, "das únicas festas verdadeiras que são as festas religiosas, pois um capricho contingente não as aplica como as festas mundanas a qualquer dia que não lhes é especialmente destinado" (PROUST, 1968, p. 167). É esse quadro encantatório que o talento de Marcel Proust nos oferece ao longo de sua obra, retomando cá e lá seus motivos, repensando-os, reorganizando-os,

1 O livro foi publicado em agosto de 2021. 
recuperando com eles as formas e os sentidos das coisas perdidas no tempo da infância. É esse mesmo quadro que nos faz desejar recuperar, também nós, os quadros de nossa memória e de nossa experiência literária que deram forma à cidade de Combray, à casa da tia Leôncia e ao rio Vivonne.

Mas qual não é nossa decepção, uma vez o jogo desfeito, de não mais encontrar Combray e seu encantamento, mas a simples cidade de Illiers, com a casa da tia Amiot, o rio Loir e sua vida habitual. Onde estão os jardins floridos, o mundo da ficção? Da cidade imaginária só nos restou o nome, hoje ligado por um tracinho de união à cidade real: Illiers-Combray. Seria essa junção dos dois nomes uma vitória da ficção sobre a realidade? Seria uma forma precária de dizer que a realidade poderia confirmar a ficção? Que o artista consiga recriar a realidade com seus meios próprios, sabemos e não podemos negar. Que o poeta possa, "com sua vontade, evocar a primavera em pleno inverno, tirar o sol do seu coração, e criar com seus pensamentos ardentes uma cálida atmosfera", já nos ensina Baudelaire em seu poema "Paisagem" (1985, p. 72). Que o pintor consiga reproduzir as nuances de luz na fachada de uma catedral em diferentes momentos do dia, em trinta e uma telas, Monet já no-lo provou. Entretanto, o mais surpreendente é que os homens, conscientes da distância entre o real e o imaginário, procurem formas de perpetuar o jogo e de garantir a ilusão. [...]

Nossas cidades estão povoadas de mitos e de ficção como nossos museus e nossas bibliotecas. Propóem-nos textos alheios, são jogos de citação que se escondem nos meandros de suas ruelas, em caminhos recônditos, em ladeiras e descidas a que não se dá muita importância. Como se quisessem nos tirar do tempo presente e nos fazer viajar na história: aqui morou fulano de tal, Praça da Bastilha, Passeio Público, Alexander Platz, Praça Washington das quantas, Pedro não sei que número, ou coisa que o valha. Ou nos fazer penetrar no tempo do imaginário como Illiers-Combray.

As cidades são como o museu e a biblioteca, que guardam em seus corredores e estantes, como as ruas e as casas de uma cidade, as representaçóes imaginárias que muitas vezes as cidades não podem oferecer. Assim como o leitor que percorre os labirintos do museu ou da biblioteca, o viajante que vai em busca das referências literárias e artísticas é um flâneur que procura em seus passeios pela cidade os elementos que falam das obras [...]. No lugar real, onde ainda existem vestígios do passado de um escritor ou de um artista, e que foi o palco de muitas representaçóes imaginárias, refugia-se o visitante, deleita-se o visitante, decepciona-se o visitante. Ali cabem seus sonhos, ali se alimentam e ali mesmo se desfazem.

As imagens sonhadas não resistem à realidade. As imagens inventadas só permitem sonhar. Deixam, no entanto, uma marca indelével, no mundo real, como a do tracinho de uniáo que une Illiers a Combray, e que oficializa, através da linguagem, de forma precária, mas real, a presença do imaginário dentro dos limites do nosso mundo (SILVA, 2020, p. 157-159). 
O texto fala por si, e acho que não é a ocasião de comentá-lo. Mas creio que nada fazia brilhar tanto o olhar de Edson quanto a possibilidade de riscar, como ele não cessava de fazer, esse tracinho de união que lhe permitia sonhar e fazer sonhar o sonho e a invenção da arte e da literatura se unindo à realidade.

Eu gostaria de concluir esta pequena homenagem com um breve depoimento pessoal. Na minha trajetória, Edson participou daqueles que são, talvez, os momentos mais memoráveis de uma vida acadêmica. Esteve em minha banca de Mestrado em 1992, na banca do concurso em que me tornei professor da UFRJ em 1994, na de Doutorado em 1996, e presidiu minha banca de promoção para titular em 2015. Curiosamente, no entanto, isso sequer me veio à lembrança quando escrevi um pequeno texto no dia de sua partida. Que reproduzo aqui para terminar:

Conheci Edson ao entrar para o Mestrado em Letras Neolatinas em 1988. Fui seu aluno desde o primeiro semestre nas disciplinas de Literatura Francesa e logo nos aproximamos. Com seu bem-humoradíssimo e sempre afiado mau humor, sua verve implicante, sua cultura imensa e sua vocação professoral, estava sempre contando histórias e explicando alguma coisa. Jamais perdia a oportunidade de dar uma aula, dentro ou fora da sala de aula, fosse sobre Baudelaire ou Flaubert, sobre a relação entre o samba e o choro, os concertos para piano de Chopin, a arquitetura barroca ou a fonética do francês. Edson foi meu primeiro parceiro na Faculdade de Letras. Foi, de fato, o primeiro a me tratar como um interlocutor de igual para igual, estimulando-me a pensar com autonomia e liberdade, ensinando-me a colocar sempre em primeiro plano as ideias que se discutem - e não a posição de quem as discute -, o que ainda hoje me parece uma prática pouco comum no cotidiano tão hierarquizado de nossa universidade. Fui com ele aos meus primeiros congressos, com ele tomei gosto pela vida acadêmica, foi ele quem me fez pensar que eu poderia me tornar um professor universitário. Fomos juntos a muitos lugares, dividindo quartos de hotel, mesas-redondas, mesas de bar, tantas caminhadas por tantas cidades, nunca deixei de aprender com ele. Compartilhamos projetos, bancas, organizamos colóquios, fizemos por 20 anos uma revista juntos. Sua aposentadoria em 2019 já tinha esvaziado um pouco para mim a Faculdade de Letras. Mas sempre mantivemos nossa rotina de almoços esporádicos, em Niterói, no centro do Rio, nos últimos anos quase sempre no Lamas, no Flamengo, muitas vezes na companhia de nossa querida amiga e colega Márcia Pietroluongo, com direito a chope, bolinho de bacalhau, filé à milanesa à francesa, e que sempre terminava com uma, eventualmente duas, dosezinhas de cachaça Magnífica. De que falamos em nosso último encontro, no dia 29 de dezembro, algumas horas antes de sua partida. Prometi, ao despedir-me, que voltaria na semana seguinte 
com o bolinho de bacalhau e a Magnífica, e fiquei feliz por poder tê-lo visto ainda sorrir.

Não houve tempo para isso, mas desde entấo vivo, vivemos todos que o conhecemos, esse futuro e essa saudade apenas - e não é pouco - na memória.

\section{Referências}

DICTIONNAIRE ANDRÉ MALRAUX. Organização de Jean-Claude Larrat. Paris: Classiques Garnier, 2015.

MALRAUX, André. Palavras no Brasil - Discours au Brésil. Organização e traduçáo de Edson Rosa da Silva. Rio de Janeiro: Funarte, 1998.

MALRAUX, André. A cabeça de obsidiana. Malraux diante de Picasso. Tradução, prefácio e notas de Edson Rosa da Silva. Rio de Janeiro: Editora UFRJ, 2021.

SILVA, Edson Rosa da. As (não-) fronteiras espaciotemporais em L'Espoir de Andre Malraux. Rio de Janeiro: Editora Rio, 1978.

SILVA, Edson Rosa da. A reflexão da literatura. Belo Horizonte: Editora Moinhos, 2020.

Marcelo Jacques de Moraes é professor titular de literatura francesa na Universidade Federal do Rio de Janeiro, pesquisador do CNPq e Cientista do Nosso Estado (FAPERJ). É autor das coletâneas de ensaios $A$ incerteza das formas, $O$ fracasso do poema e Lingua contra língua (7 Letras), e do volume Christian Prigent (Coleção "Ciranda da Poesia", Eduerj). Traduziu diversos escritores e ensaístas franceses, entre os quais, mais recentemente, Georges Bataille, Christian Prigent, Marielle Macé e Jean-Christophe Bailly. Dirige atualmente a Editora da UFRJ.

E-mail: mjdemoraes@gmail.com 